\title{
A Comprehensive Study on Business Analytics
}

\author{
Bhoomraogari Sai Teja \\ Department of Electrical and Electronics Engineering \\ Mahatma Gandhi Institute of Technology \\ Hyderabad, India
}

\begin{abstract}
The decision-making methods have in the past been the topic of several investigates, both within as well as additionally outdoors your business administration area. Several authors have incorporated significantly to boost the study of the issue. An important spot on this location was delivered by Simon, which offered an exceptional payment covering worrying excess of reason in decision making. The searchings for affirm that $\mathrm{BA}$ is winding up being extremely well understood one of a lot of providers worldwide, being used if you desire to reinforce business procedure effectiveness. This paper gives an extensive overview of business analytics.
\end{abstract}

\section{Keywords-Business Analytics, BI, publications}

\section{INTRODUCTION}

The decision-making processes have traditionally been the subject matter of much researches, each within as well as outdoors your business administration area. Various article writers have added significantly to improve the assessment of the concern. A necessary spot on this business was provided through Simon, that used an impressive remittance evaluating concerning extra of rationality in decision making. The results confirm that $\mathrm{BA}$ is coming to be successfully recognized as one of a great deal of business worldwide, being administered to strengthen business procedure effectiveness

Across a variety of social and economic sectors, organizations report as well as keep big amounts of files on their individuals, products, along with solutions they provide. To utilize this technical reports kept and additionally preserved in several electronic platforms such as records resources and also records warehouses, as well as to turn it right into doable understandings a brand-new area called Business Analytics (Undergraduate's Degree) additionally called Business Intelligence (BI) or maybe Big Data (BD) has emerged over the final handful of years. Undergraduate's Level has expanded as well as also come to be a facet of every primary business decision approaching, and likewise, it has the prospective to boost organizations as it urges selection producers with data as well as additional supports each one of all of them to introduce vital, working, and military choices. BA has come to be a potential business enabler in both social and also economic sectors as well as is among the fastest establishing places. Some suppliers have also designed their whole business styles around this suggestion and also handle their companies based upon their ability to gather, evaluate, and also act on information (Davenport, 2006). Offered the straightforward truth that our group resides in a globe of complementary people as well as likewise computer systems producing and helping make so much more records available, BA stores exceptional assurance for agencies around several industries. An Undergraduate's Degree may be important to a company's methods as well as a crucial facet of decision making procedure. It might modify the strategy firms harness their info generated inside including deal reports and even gathered coming from exterior sources like social media sites networks, smartphones, net- internet sites, and add relevant information sensing devices. It offers selection makers the electric power to integrate several information sources along with find out more understandings in them, consequently permitting all of them to acquire an all-natural sight of their business as well as consumers, boost useful effectiveness, move toward a data-driven decision-making environment, and also give business-critical choices. BA can conveniently help organizations make use of the well worth of historical and also real-time reports by taking advantage of the power of logical and likewise algebraic types. Utilizing such styles, a manager can effortlessly monitor important metrics and also functioning information as well as service as well as also perform efficiency. Via carrying out BA attempts in their organizations, choice manufacturers might feature inconsonant records information, projection trends, boost performance, see crucial productivity indications, identify business chances, as well as also make better and also upgraded collections. Even more, by leveraging BA abilities in addition to designs, decision manufacturers may recognize business motorists of business outcomes, line up business goals, and likewise the business's development, also, to develop value-based methods and fact-based understandings of business performance examination. The function of the particular investigation study is twofold: to start with, it produces a try out to provide an operating interpretation, past, and also a testimonial of BA/BI/Big Information idea as well as additional process. Additionally, it details if $\mathrm{BA} / \mathrm{BI} / \mathrm{BD}$ is, however, another fad and even a business enabler.

Alongside enhancing globalization of markets, brutal competition, increasing the velocity together with changes in market ailments as well as consumer needs, all market people in addition to companies experience brand new problems. Down the road, business is going to have the potential to state on their own, that may adjust to these wellness disorders, that can respond flexibly and additionally promptly to modifications while simultaneously sustaining their prices controlled. Consequently, however, specific knowledge of the here and now company and also market scenario is vital. To guarantee this in addition to supply control along with the relevant details needed to have to invite their prep work in addition to decision-making, cutting-edge details in addition to interaction systems are taken advantage of. Given that the 1960s, several techniques have been developed for such physical bodies, which have found yourself being recognized under many different labels including Observing Relevant 
Info Tools (MIS), Selection Help Answer (DSS), or perhaps Supervisor Particulars Unit (EIS). Today, the health condition of Business Intelligence (BI) has happened established both online as well as in research. BI explains strategies like picking up, sparing, handling, studying as well as offering firm reports.

In the latest opportunities, Business Intelligence has turned into one of the leading topics in German and around the world IT market. Hereof, the relevance of business has boosted considerably. Through making use of BI systems, companies are composed of creating their business-critical documents as well as processes uncomplicated in addition to intelligence. Similarly, workers are going to undoubtedly possess the ability to make better selections, accomplish the called for results a lot faster, in addition to regularly develop each one of them. An additional benefit of BI devices is that business can make their customer along with merchant alliances a great deal extra successful, minimize expenditures, reduce threats in addition to increase incorporated market price. Without the use of BI devices, huge quantities of information are really delivered, but afterward, they spread complications along with basically make complex business.

Several years earlier, practically only big business and firms revealed interest rate, right now this content has found yourself being steadily captivating for start-up carriers Considered that there they uncovered what ability can be utilized with Business Intelligence. One reason for this is really that the BI course has ended up being considerably more affordable and extra budget-friendly for many startups. For instance, the BI market is overloaded via software program vendors (like SAP, IBM, SAS, Microsoft, and available source providers) that point out to start-ups. As an alternative, enhancing reasonable stress and the requirements to become capable to rely on depended on information rapidly and also in each time are sure solid needs.

\section{TYPES OF ANALYTICS}

3 types of analytics are teamed up with using affiliations: clear-cut, predictive, and prescriptive.

Clear-cut analytics utilizes business intelligence and records mining to give trending facts on previous or found activities. Detailed analytics workouts down right into data to uncover info like the frequency of celebrations, the price of functions, and likewise the root cause of analyses (IBM, 2013). Conclusive analytics supplies notable understanding right into business efficiency in addition to permits clients to a great deal far better keep an eye on in addition to handle their business operations.

Preparing for analytics uses a range of styles as well as additional approaches to anticipate prospective results based on historic along with present records (Gandomi as well as Haidar, 2014). In anticipating choices in, data is gathered, an analytical type is made, prophecies are created, as well as the model is sanctioned as included files seem (Gartner IT Reference. n.d). Predictive analytics is what converts big data into purposeful, useful business applicable info (Abbott, 2014). It releases the electrical energy of data and also permits selection makers to profit from information just how to foresee the prospective routines of individuals.

Prescriptive analytics may be pointed out as a collection of algebraic techniques that computationally compute an assortment of high-value different actions or collections that gave a challenging collection of reasons, criteria, as well as restrictions, to boost business effectiveness (Lustig and so on, 2010). Prescriptive analytics enables decision-makers to absolutely not only have a look at the future of their function important procedures as well as discover the possibilities, yet it, also reveals the absolute most efficient treatment to take advantage of that understanding in a timely way.

\section{THE IMPORTANCE OF DECISION MAKING}

Globalization sticks at nothing around the planet have accessibility to the same resources, including components, elements, things, and additionally even people. As firms also use equivalent contemporary innovations, competition is generating business procedures to merge in the direction of similar criteria. This is leaving behind the premium quality of a business's decision making as its main methods for outperforming its competitors.

Digitization, however, is steering down costs and additionally leading to commoditization. Intangibles allow a business to distinguish stemming from its competitors. They are currently the main licensed operators of the value that a business may simply develop. The premium quality of its own decision making enables a business to adapt even more immediately than its competitors to the chances in addition to risks delivered as a result of the digital age as well as the innovations in its very own markets. It is also the key unobservable that opens up the achievable to set up other intangibles within the business, like its own sensible position, its own firm's reputation and online reputation, the top quality of its people, its psychological funds, and also precisely how properly it implements its options.

Solutions need to therefore take care of the danger of predisposition in decision making through guaranteeing that their assortment manufacturers do undoubtedly not unnecessarily work out exclusive sound judgment based upon past know-how or even guided by specific objectives. As an option, they must strive to be evaluated and reasonable. Choices have to be based upon proof delivered via proper information and also

on the attentive study with a concentrate on stakeholder market value. There must also be clearness as well as likewise accountability in decision making to advise a community of mutual functions, as well as mutual, depend on, absolutely stable along with the Global Control Review Concepts.

A private perspective as well as also suspicions are still important yet they should be looked at in the situation of what the information today available notifies our group. The expert system can effortlessly create algorithms and also pinpoint partnerships, yet there is still a criterion to add this individual measurement to produce understandings.

\section{RECOMMENDED ACTIONS OF BA}

Analytics is still an arising specialty so our experts may conveniently absolutely not supply a well-defined checklist of 
the activities that providers should take. Possessing claimed that some usual styles have emerged from our meetings:

1. All interviewees possessed a crystal clear understanding of their business, its method for the future along with what it needs to complete to produce worth.

2. They have all offered a sizable notion to exactly how to 'participate in the dots' in addition to determine causal hookups to compute what remedies, as well as examination, are critical to handle your business's productivity.

3 . In lots of providers, information often tends to remain in addition to the 'supervisor' of the procedure that produces it; our interviewees, however, looked out to the information offered throughout their business.

4. Sometimes documents supervisors give an evaluation of their details, and companies might have wallets of expertise in studying details. The suitable method, nevertheless, appears to become to possess one center of expertise, either within or even functioning alongside the monetary technique, and a way of life that permits the sharing of applicable info all over willpowers.

5. There is an exchange between understandings as well as decision making. Insights are required to educate decisionmakers. But examination and additionally musing may supply brand new ideas, about the individual process as an example, that can easily result in a need to take a decision.15.

6. Expert system and machine learning can identify relationships and also patterns but there is still a requirement for the private size to examine this information.

7. Collaboration in addition to business colleagues was a redoing concept. If you want to change reasonable know-how right into commercial outcomes, people need to have to operate well entirely throughout specialties.

\section{BUSINESS ANALYTICS PUBLICATIONS}

There are certain that publications on BA subjects have ended up being a whole lot much more preferred in both tracks as well as IT diaries. The downright most required second of BA compositions happened when it got extra exposure using the journal of Davenport's paper "Competing on Analytics" in the Harvard Business Assessment. Later in a publication, likewise clarified Undergraduate's Degree as the detailed use information, statistical and quantitative analysis, useful and also predictive styles, and also fact-based surveillance to guide selections and also tasks.

[3] proposed that business needs to take into account 2 distinctive domains relating to Undergraduate's Degree: i) Internal Analytics: Financial, Manufacturing, Investigation \& growth, Human Resources; and also ii) External Analytics: Customer and also Seller. To find near to such domains, companies should "obtain the reports suit" preparing big amounts of excellent files to develop blooming logical environments. Analytical competitions need a very clear business strategy where supervisors have to consider what vital methods in addition to crucial initiatives will be advanced based on the most effective analytics.

Besides Davenport's publications, some relevant documents should certainly be highlighted. In the paper Business analytics in source establishments-- The dependent outcome of business procedure readiness, analyzes the impact of making use of business analytics on source building efficiency, checking out the tweaking data processing needs at different supply facility treatment maturity levels.

An extra appropriate journal is The impact of business analytics on source establishment performance by [4] that study the partnership in between logical capabilities in the organizing, source, make and also deliver region of supply chains and their impact on business efficiency, taking info tool support as well as business treatment alignment as mediators. The authors establish that the result of the small number of information units preserve is much more powerful than the result of business technique positioning, highlighting the market value of an agency's use of its very own data sources, explicative and expecting variations as well as fact-based management to guide its very own selections.

One more suitable paper that provides a new viewpoint of a BA is Skill and analytics: new approaches, better ROI. Within this paper, writers connect BA Level to Human Resources strategies and likewise pop the question one step ladder of analytical HR usages. In this particular emotion, some techniques have an extra effective than others and maybe visualized as a ladder of rational class.

Additionally, the paper Integrating business analytics right into vital managing offered an applicable addition through presenting that the practical make use of business analytics is completed through blending 3 numerous usage perspectives: i) the IT Located asks for; ii) the tracking bookkeeping procedures, and iii) the analytical treatments asks for.

A whole lot even more merely recently, it may additionally be revealed a paper developed using made it possible for Modifying e-services evaluation information right into business analytics taking advantage of worth concepts Enhancing e-services evaluation data straight into business analytics utilizing market value concepts. In this paper the authors highlight just how the website has been examining big volumes of information nowadays, suggesting that improving these reports into favorable business analytics requires a significantly better understanding of the endurances and also weaknesses of the e-service, assisting in its enhancement and additionally marketing. The article writers recommend along with sanction a strategy for altering specific analysis information into sensible business analytics and also point out worth type for e-services.

Despite having a deficiency of papers launched in rated control publications involving BA, they work together for cultivating the guideline, showing BA as a surfacing intended both for experts as well as likewise academicals.

\section{BIBLIOMETRIC RESEARCH}

Even though it was achievable to situate simply 23 launched clinical reviews in the time structure 20022012 , it is critical to highlight a quite exceptional 
improvement starting in 2006. As may be seen in Body system 1, after a height in 2008, there is an enriching considerable amount of publications on the topic year through the year since 2009 , together with a variety of other tops in 2011 as well as 2012.

\section{Nr. of Publications per year - Academic Journals}

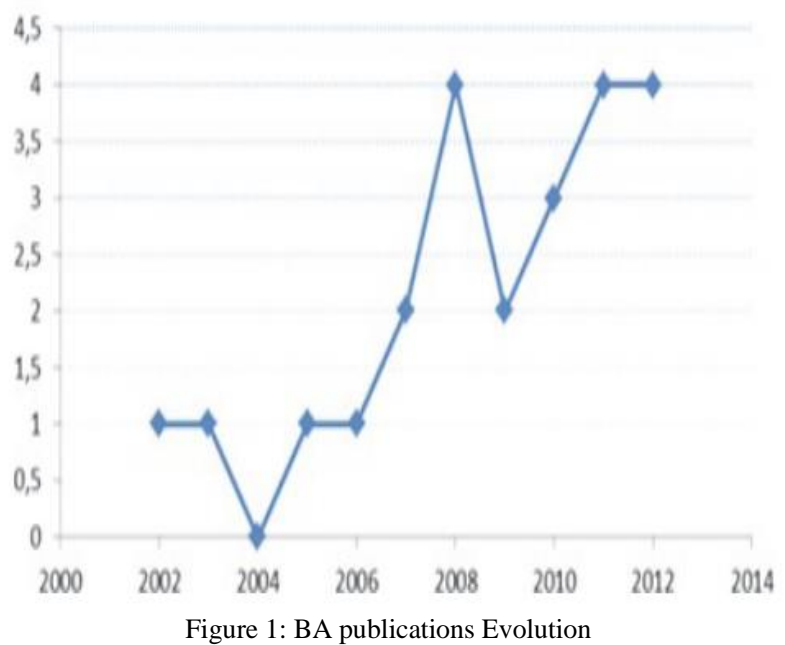

It is vital to mention that the majority of the articles in the Undergraduate's Degree have really seemed to be in unranked diaries. Practical review in BA has in fact associated with leading- course journals just to a moderate degree so far. Out of 23 documents situated, merely 5 documents were in fact discharged in publications detailed at Publication of Citation Updates. Within this sense, it encourages that a boost of write-ups in position diaries could be expected along with establishing a degree of recognition and also moving on the growth of the investigation place in the future.

There is a big quantity of publications that have actually already released BA files. It was really achievable to situate 137 publications in IT and Business focused publications in the last one many years (e.g. eWeek, InformationWeek, Computer World, and so on).

Such proofs opening up Business Analytics as a developing business that it is, in fact, luring much interest rate from the experts' community, however, still beginning as an academic examination subject. In this certain feeling, it can be embodied from this that Business Analytics is actually an exceptional odds as an investigation industry for academicals considering that specialists are actually asking for even more relevant information as well as expertise concerning it.

Table 1 sums up the analysis study publications detailed files taking into consideration 3 viewpoints: Meta point of view, Content-based perspective, and also a technical viewpoint

Stemming from the meta-perspective, as quickly as there are actually simply a handful of BA Degree pragmatic documents, the worths of the ideas are actually lowered as a whole, especially pertaining to enhancements per magazine and annually. The criterion of 2.3 authors per blog post lives in agreement with the most element of articles posted in scholarly publications.

\begin{tabular}{|c|c|c|}
\hline Meta-perspective & & \\
\hline Continbutions per year Number & 2,1 & \\
\hline Contributions per journal & 1,0 & \\
\hline Contributions per countyyregion & 22 & \\
\hline Contibutions per researcher & 0,4 & \\
\hline Participating authors per article & 2,3 & \\
\hline Content-based perspective Context & Nr. & $\%$ \\
\hline Technology oriented & 6 & $27 \%$ \\
\hline Businessoriented & 9 & $41 \%$ \\
\hline Technology / Business oriented & 9 & $41 \%$ \\
\hline Methodical perspective Researchmethod & Nr. & $\%$ \\
\hline Survey & 5 & $23 \%$ \\
\hline Theorefic & 11 & $50 \%$ \\
\hline Casestudy & 8 & $36 \%$ \\
\hline Action research & 0 & $0 \%$ \\
\hline
\end{tabular}

Table 1: Papers classified by research perspectives.

Originating from the technical standpoint, like BA Level checks into are actually evenly all new in the academic setting, many publications are in fact scholastic $(43.48 \%)$ or even based upon case study (34.78\%). Survey procedures are really represented by $21.74 \%$ having said that nearly all of the Surveys were actually launched in position publications. Making use of research study for Undergraduate's Degree analysis is covered with [4] as a method of handling locations that are actually still in the understanding, finding in addition to recap stage, being strongly highly recommended as an analysis technique in a surfacing area

In fact, a BA is actually ending up being a necessary complication one of the sensible carriers. On contrary, in regards to scholarly problems, it has a lengthy and additionally abundant strategy in advance. This need can be identified when our experts wish to the volume of publications in nonclinical publications illustrating exactly how attractive a BA is really for experts. If you wish to perform a suitable role in the scholastic setting, scientists coming from around the world ought to be actually urged to set up brand new scientific check out relating to BA.

\section{CONCLUSION}

In fact, a BA is actually ending up being a necessary complication one of the sensible carriers. On contrary, in regards to scholarly problems, it has a lengthy and additionally abundant strategy in advance. This need can be identified when our experts wish to the volume of publications in nonclinical publications illustrating exactly how attractive a BA is really for experts. If you wish to perform a suitable role in the scholastic setting, scientists coming from around the world ought to be actually urged to set up brand new scientific check out relating to BA. This paper provided a comprehensive overview of business analytics. 


\section{REFERENCES}

[1] Baars, H, Kemper, HG. Management Support with Structured and Unstructured Data - an Integrated Business Intelligence Framework. Information Systems Management 2008; 25:2. 132148.

[2] Bagozzi, RP. Causal Methods in Marketing, New York: John Wiley and Sons; 1980.

[3] Barney, JB. Firm Resources and Sustained Competitive Advantage. Journal of Management 1991; 17:1. 99-120.

[4] Baron, RM, Kenny, DA. The Moderator-Mediator Variable Distinction in Social Psychological Research: Conceptual, Strategic, and Statistical Considerations. Journal of Personality and Social Psychology 1986; 51. 1173-1182.

[5] Bassellier, G, Benbasat, I, Reich, BH. The Influence of Business Managers' IT Competence on Championing IT. Information Systems Research 2003; 14. 317-336.

[6] Bollen, KA, Stine, R, Direct \& Indirect Effects: Classical and Bootstrap Estimates of Variability. Sociological Methodology 1990; 20. 115-140.

[7] Chin, WW. The Partial Least Squares Approach to Structural Equation Modeling. Modern Methods for Business Research, Marcoulides, GA, Editors. Mahwah, NJ, Lawrence Erlbaum Associates; 1998. 195-336. 